\title{
MONITORING FREEZE INJURY AND EVALUATING LOSING TO SUGAR-CANE USING RS AND GPS
}

\author{
Zongkun Tan ${ }^{1,2, *}$, Meihua Ding ${ }^{1,2}$, Xin Yang ${ }^{1,2}$, Zhaorong Ou ${ }^{1,2}$ \\ ${ }^{1}$ Remote Sensing Application and Test Base of National Satellite Meteorology Centre, \\ Nanning, China, 530022 \\ ${ }^{2}$ GuangXi Institute of Meteorology, Nanning, China 530022 \\ * Corresponding author, Address: GuangXi Institute of Meteorology, Nanning, 530022, P. R. \\ China,Tel:+86-771-5875207,Fax:+86-771-5865594,Email:tanzongkun@163.com
}

Abstract: From Jan 12th to Feb 12th, 2008, the most severity cold chilling and freeze injury weather took place during the last 50 years in the southern of China. Sugar-cane was suffered injury severity. However, the losing of sugar-cane which it was aroused by this weather disaster had not been exactitude evaluated till on Apr 1st, 2008. It was not only affected the sugar-cane ordinary harvesting and crushing, but also affected reserving sugar-cane seed for planting. Freeze injury is common disaster for sugar-cane in southern of China, and monitoring freeze injury using RS and GIS are of great economic significance, but little research work about it has been done in China. Freeze injuring is not only related to crop growth stage and the cold air intension from northern to southern and weather types, but also consanguineous related to land form and physiognomy and geographical latitude and height above sea level etc and crop planting spatial distribution. The case study of Guangxi province which is the biggest region of sugar-cane planting in China in this paper, the values of sugar-cane NDVI among the freeze injury occur former and after in early 2008 and without freeze injury occur in the same term 2007 were analyzed and compared based on the sugar-cane planting spatial distribution information which were carried out by using multi-phase EOS/MODIS data. The result showed that it was not only commendably reflected the spatial distribution of freeze injury but also reflected the sugarcane suffered from degree using the values of sugar-cane NDVI of freeze injury occur former and after. The field sample investigation data of using GPS was integrated with the NDVI, the evaluation of region sugar-cane suffer from freeze injury losing could quickly and exactly realize.

Please use the following format when citing this chapter:

Tan, Z., Ding, M., Yang, X. and Ou, Z., 2009, in IFIP International Federation for Information Processing, Volume 293, Computer and Computing Technologies in Agriculture II, Volume 1, eds. D. Li, Z. Chunjiang, (Boston: Springer), pp. 307-316. 
Key words: Cold Chilling, Freeze Injury, Sugarcane, Losing, RS, GPS, Evaluating.

\section{INTRODUCTION}

Weather disaster research focusing on disaster losing evaluation has long attracted the attention of the weather disaster community because disaster losing evaluation results are the basis for government officer anti-disaster and rescue disaster and rebuild after disaster. Scientists and practitioners have made great efforts in developing advanced disaster losing evaluation approaches and techniques for improving disaster losing evaluation accuracy (Yang Bangjie \&Wang Maoxin etc, 2002, Zhang Xuefen \&Chen Huailian, 2006). However, weather disaster losing evaluation remains a challenge because many factors, such as the complexity of the landscape and physiognomy in a study area, and crop spatial distribution, and weather disaster occurs and its continuance and intension spatial distribution, and experiment and knowledge of person who investigated crop suffering from weather disaster, may affect the accuracy of disaster losing evaluation. Although much previous research and some books are specifically concerned with disaster losing evaluation, a comprehensive up-to-date of disaster losing evaluation approaches and techniques is not available.

In view of the most severity continuance low air temperature and rainy and snowy freeze injury weather had taken place during the last 50 years in the southern of China since Jan 12th to Feb 12th, 2008. Sugar-cane and other sub-tropic crops were suffered injury severity. However, due to the disaster losing evaluation is a complex system that may be affected by many factors, and the methods of monitoring are draggle and the instruments of monitoring are lack, the losing of sugar-cane which it was aroused by this weather disaster had not been exactitude evaluated till on Apr 1st. 2008, It was not only affected the sugar-cane ordinary harvesting and crushing, but also affected reserving sugar-cane seed for planting, and the price of sugar once a time appeared abnormity wave in our country. Consequently, the exactly and quickly evaluating disaster losing have become a focus issue for government officer.

In this paper, the biggest province of sugar-cane planting in China was selected as the study area. The objectives of this research were to: (1) find out the way of identify and extraction of sugar-cane planting spatial distribution information in hilly, mixture vegetation and cloudy in 2007/2008 year crushing season, Guangxi; and (2) the retrieve a suitable monitor model for sugar-cane cold chilling and freeze injury based on EOS/MODIS data, and (3) find out a method of evaluation sugar-cane 
disaster losing based on remote sensing and geographical information systems.

\section{METHODS AND MATERIAL}

\subsection{Study area}

The study area is located in Guangxi province, south of China. It latitude is $20^{\circ} 54^{\prime} \sim 26^{\circ} 23^{\prime} \mathrm{N}$ and longitude is $104^{\circ} 29^{\prime} \sim 112^{\circ} 04^{\prime} \mathrm{E}$. Its total area is $236700.0 \mathrm{~km}^{2}$. It belongs to monsoon region of south subtropical zone and north tropical zone without four clearly demarcated seasons of spring, summer, autumn and winter. The climate here is hot and humid in summer and warm and dry in winter. For sugar-cane and other sub-tropic crops, however, Guangxi province is the region where the cold chilling and freeze injury occurs more frequently in winter than other provinces in China. For example, five times cold chilling and freeze injury disaster occurred in Guangxi province in recent decade. Among then, approach 90\% counties of Guangxi province occurred severity radiate frost and freeze injury in 1999, and approach $55 \%$ to $60 \%$ counties of Guangxi province occurred severity radiate frost or freeze injury in 2001 and 2003 and 2004, and the most severity continuance low air temperature and rainy and snowy freeze injury weather occurred during the last 50 years from Jan 12th to Feb 12th, 2008.

In 2006/2007 year crushing season, sugar-cane planting area approach $853000 \mathrm{hm}^{2}$, the yield of sugar over $7.08 \times 109 \mathrm{~kg}$ in Guangxi province, which sugar yield approach $65 \%$ of the whole country. However, the sugarcane planting area up to $95000 \mathrm{hm}^{2}$, and the yield of sugar estimated approach $9.30 \times 109 \mathrm{~kg}$ in $2007 / 2008$ year crushing season.

\subsection{Data acquisition}

In this paper, EOS/MODIS imageries obtained from Dec 1st, 2006 to Feb 28th, 2008, whose path/row is $1151 / 1230$. When the data was obtained, more than one county without cloud or little cloud images were selected, then they were synthesized one or more images in the same month. The weather and climate data were required from Guangxi climate center, and the sugar-cane suffered weather disaster field investigation data from Luzhai and Laibin and Longan and Tiandong counties where are the main sugar-cane planting region in Guangxi province. 


\subsection{Methods}

Due to the relationship between vegetation indices calculated by different algorithms, reflectance of bands and field measurements of NDVI, we can retrieve NDVI using EOS/MODIS data. With this relationship, a NDVI retrieval model for study area can be established. A specific flow chart of retrieval technique is shown as Figure 1.

Based on the above flow chart of technique, detailed steps are described as follows:

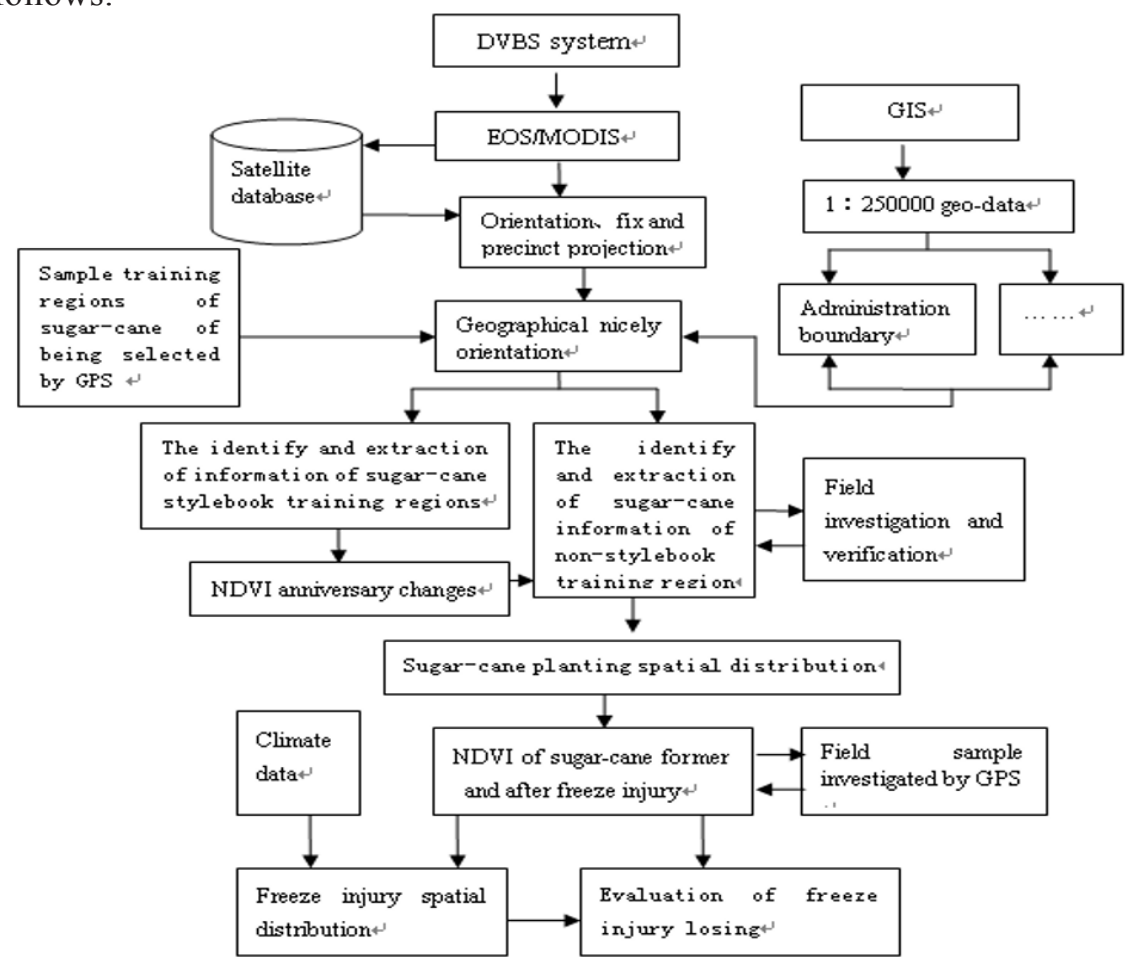

Fig1. The flow chart of the identify and extraction of sugar-cane planting space distribute information and evaluation of freeze injury losing based on EOS/MODIS data

\section{Inversing reflectance for EOS/MODIS imagery}

The objective of atmospheric correction for EOS/MODIS data is to attain related parameters which can indicate the vegetation inherent properties of the region. Since the remotely sensed image was affected by reflective solar energy, solar elevation, zenith angle, the thickness of aerosol and the bidirectional scattering due to the mutual influence of ground environment factors, we should take into account both atmospheric and bidirectional scattering to obtain accurate ground reflectance. Because the parameters of 
atmospheric profile based on measurements data or standard atmospheric profile were not established in China, in this paper we adopted international standard parameters of atmospheric profile to correct EOS/MODIS image.

\section{Obtaining characteristic parameters of vegetation}

Due to the chlorophyll and inner architecture of foliage, a special reflective spectrum of vegetation foliage was formed like intensive absorption in the red waveband and intensive reflection in the near infrared waveband. By the reflectance difference varied in the red and the near infrared waveband, we can calculate related parameters that indicate the conditions of vegetated surfaces, such as normalized difference vegetation index (NDVI) which is a simple, effective and experiential measurement to vegetation activity. To some extent, NDVI indicates the vegetation information of status and succession.

NDVI, a parameter (range $-1 \sim 1$ ) denoting the ground vegetation coverage can be derived from the reflectance in the red and the near-infrared wavebands. This equation reads:

$$
\mathrm{NDVI}=\frac{\rho_{\mathrm{NIR}}-\rho_{\mathrm{R}}}{\rho_{\mathrm{NIR}}+\rho_{\mathrm{R}}}
$$

From the equation we can see that in the water area and roadway area and city or town area, theirs value of NDVI are below 0 or approach constant value in different seasons. But for the land surface with cover foliage, NDVI ranges from 0.1 to 0.7 . NDVI has been applied in many fields, such as land cover or change, vegetation and environment change, net primary productivity and the assessment of crop yield.

In addition, because of the value of NDVI will be change when crops suffer from weather disaster, we can compare the difference of NDVI former and after disaster to distinguish the spatial distribution of weather disaster intention and evaluate the losing of crops.

\section{Sample training regions of sugar-cane of being selected by GPS}

To the same foliage, its value of NDVI is various with its growth process. As result, the values of NDVI between foliages are diversity in different seasons. In order to mastery the spectrum characteristic of sugar-cane and distinguish sugar-cane from many kinds of foliages, some sample training regions of sugar-cane in different county of Guangxi were selected by GPS.

\section{Field sample investigated by GPS to validate weather disaster intension}


In order to validate weather disaster intension spatial distribution whether relate with the NDVI of former and later disaster difference size, some field sample investigating regions of NDVI difference size were selected by GPS in the main sugar-cane planting counties of Guangxi province.

\section{The identify and extraction of sugar-cane planting information based on EOS/MODIS data}

In the first place, the values of NDVI of sample training regions of sugarcane during the main growing seasons were calculated. As result, we could find the variety trend of curves of sugar-cane in different regions being consistent.

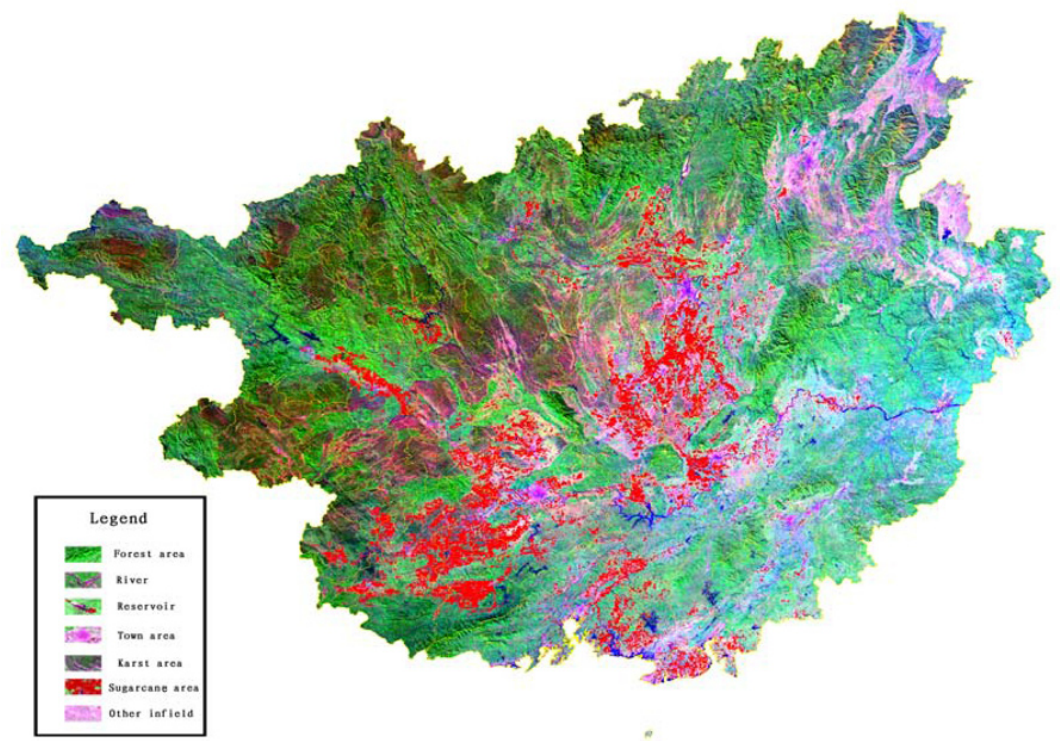

Fig.2. The imagine of sugar-cane planting and its spatial distribution based on EOS/MODIS in Guangxi province, 2007

For the sugar-cane, its growth lasting more 8 to 12 months, and the main of crops is sugar-cane in Guangxi province during winter, and the areas of sugar-cane cover are reduced during crush season. When the crush season was over, the values of sugar-cane planting areas approached 0 .

And the same time, corn and rice and soybean, theirs growth (from sowing to harvest) are general lasting 3 or 4 months. The south subtropical zone and north tropical zone forest growth lasting more than 12 months, but its value of NDVI anniversary approach constant. Consequently, the curves of NDVI variety in different foliages during the main growth seasons are difference. We can use the Maximum likelihood to extract the information of sugar-cane planting and its spatial distribution through the calculation of multiple-phase MODIS-NDVI from different foliages in Guangxi province. 
The result shows that the information of sugar-cane planting and its spatial distribution in 2007 were clearly in remote sensing imagine (Fig2). The survey of field also showed that the information of sugar-cane planting based on multiple-phase EOS/MODIS data was highly reliable and truth.

\section{MONITORING FREEZE INJURY TO SUGARCANE BASED ON RS}

Because of sugar-cane origins in the tropic region, its growth demands higher temperature. More than 50\% sugar-cane area are distributed in the northern of sub-tropic in China, however, the air temperature of winter in the northern of sub-tropic is difficult to satisfy sugar-cane growth need. Lots of investigation and experiment data shows that sugar-cane physiological active will be limited when the air temperature approach to $4^{\circ} \mathrm{C}$, and sugar-cane lamina chlorophyll contain will be violent descent and photosynthesis will be inhibited as soon as the air temperature drop to $0^{\circ} \mathrm{C}$. If frost and freeze injury continuance, the lamina gradually turns to yellow and withered, and sugar-cane growth point and lateral bud emergence death, and stem of sugarcane maybe appear water boil symptom and its organs maybe deterioration, and contain of sugar will drop and till the root lateral bud under soil emergence death. Consequently, the value of sugar-cane NDVI former and later frost (or freeze injury) must be changed. We can accord the spatial distribution of the value of NDVI former and later frost (or freeze injury) difference size to distinguish the spatial distribution of weather disaster intention.

In fact, we can see the value of sugar-cane NDVI between continuance low air temperature and rainy and snowy freeze injury weather former and later being distinctness discrimination from the table1.

Table1. sugar-cane NDVI of freeze injury former and later and without freeze injury based on sunny counties

\begin{tabular}{|c|c|c|c|c|c|c|c|c|c|c|}
\hline & \multicolumn{2}{|c|}{ Guangxi } & \multicolumn{2}{|c|}{ Laibin } & \multicolumn{2}{|c|}{ Guigang } & \multicolumn{2}{|c|}{ Liuzhou } & \multicolumn{2}{|c|}{ Hechi } \\
\hline & NDVI & $\%$ & NDVI & $\%$ & NDVI & $\%$ & NDVI & $\%$ & NDVI & $\%$ \\
\hline \multirow{3}{*}{$\begin{array}{c}\text { Jan 4th, } \\
2008\end{array}$} & $>0.3$ & $53 \%$ & $>0.3$ & $21 \%$ & $>0.3$ & $28 \%$ & $>0.3$ & $27 \%$ & $>0.3$ & $60 \%$ \\
\hline & $0.2-0.3$ & $45 \%$ & $0.2-0.3$ & $73 \%$ & $0.2-0.3$ & $65 \%$ & $0.2-0.3$ & $70 \%$ & $0.2-0.3$ & $39 \%$ \\
\hline & $0.0-0.2$ & $2 \%$ & $0.0-0.2$ & $5 \%$ & $0.0-0.2$ & $7 \%$ & $0.0-0.2$ & $3 \%$ & $00 .-0.2$ & $1 \%$ \\
\hline \multirow{3}{*}{$\begin{array}{c}\text { Feb 15th, } \\
2008\end{array}$} & $>0.3$ & $4 \%$ & $>0.3$ & 0 & $>0.3$ & $9 \%$ & $>0.3$ & $2 \%$ & $>0.3$ & $1 \%$ \\
\hline & $0.2-0.3$ & $38 \%$ & $0.2-0.3$ & $24 \%$ & $0.2-0.3$ & $36 \%$ & $0.2-0.3$ & $52 \%$ & $0.2-0.3$ & $37 \%$ \\
\hline & $0.0-0.2$ & $58 \%$ & $0.0-0.2$ & $76 \%$ & $0.0-0.2$ & $55 \%$ & $0.0-0.2$ & $46 \%$ & $0.0-0.2$ & $62 \%$ \\
\hline \multirow{3}{*}{$\begin{array}{c}\text { Feb 4th } \\
\text {,2007 }\end{array}$} & $>0.3$ & $30 \%$ & $>0.3$ & $12 \%$ & $>0.3$ & $28 \%$ & $>0.3$ & $4 \%$ & $>0.3$ & $5 \%$ \\
\hline & $0.2-0.3$ & $64 \%$ & $0.2-0.3$ & $79 \%$ & $0.2-0.3$ & $65 \%$ & $0.2-0.3$ & $80 \%$ & $0.2-0.3$ & $68 \%$ \\
\hline & $0.0-0.2$ & $6 \%$ & $0.0-0.2$ & $9 \%$ & $0.0-0.2$ & $7 \%$ & $0.0-0.2$ & $16 \%$ & $0.0-0.2$ & $27 \%$ \\
\hline
\end{tabular}


Compared the values of sugar-cane NDVI between cold chilling and freeze injury occur in early 2008 and without cold chilling and freeze injury occur in the same term 2007, it is not difficult to find the values of sugarcane NDVI also being distinctness discrimination.

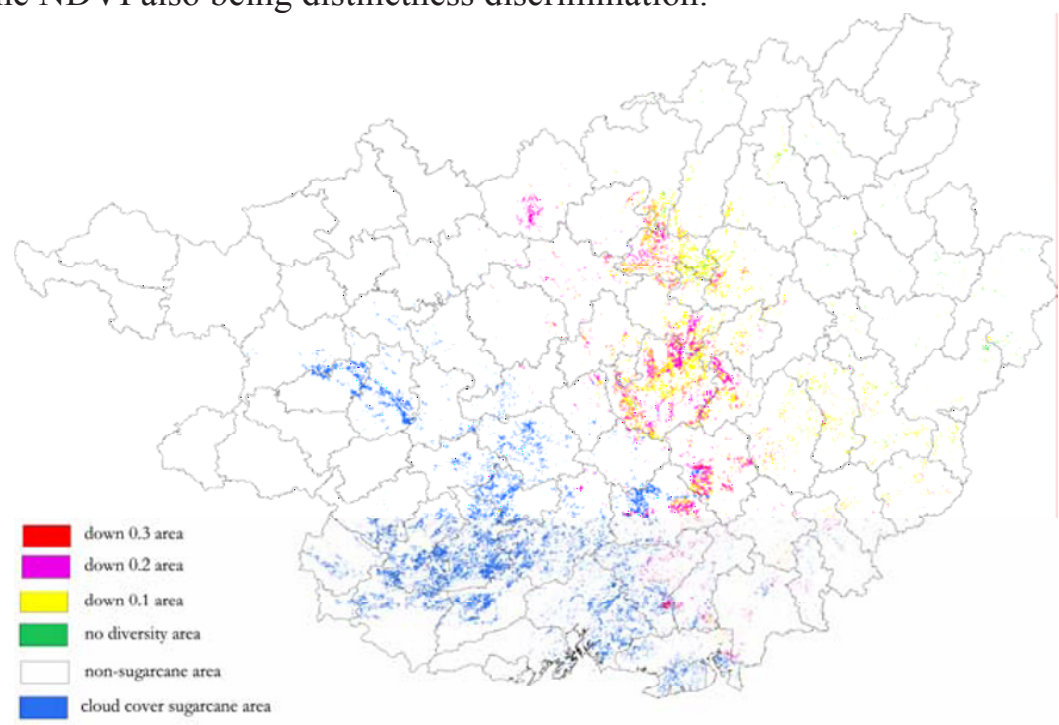

Fig3 the imagine of sugar-cane NDVI reduce after freeze injury

In order to find the relationship between sugar-cane NDVI difference size spatial distribution and weather disaster intension distribution, the difference of sugar-cane NDVI former and later freeze injury was calculated in this paper. From the figure 3, we can find the sugar-cane NDVI of later freeze injury descend is discrimination in different region. In view of sugar-cane breeds planting spatial distinction and the capability of sugar-cane breeds resist freeze injury, further more, colligating the climate data of freeze injury, we can judge the freeze injury intension spatial distribution.

\section{LOSING OF SUGAR-CANE EVALUATION}

Based on the sugar-cane NDVI difference size spatial distribute, some of samples sugar-cane NDVI difference size in Luzhai and Longan and Tiandong etc counties where the main sugar-cane planting regions of Guangxi province were selected from remote sensing imagine first, then according the result of classification to sample field investigate by GPS. The results showed that the sugar-cane NDVI difference size could reality reflect the disaster intension. 

$R S$ and $G P S$

Table 3. area percent of sugar-cane NDVI different among freeze injury former and later and normal year in sunny region of Guangxi province, China

\begin{tabular}{ccccccc}
\hline & NDVI difference & Guangxi & Laibin & Guigang & Liuzhou & Hechi \\
\hline \multirow{2}{*}{ Difference of } & $\leq 0$ & $4 \%$ & $1 \%$ & $3 \%$ & $6 \%$ & $1 \%$ \\
Jan,4th and & $0.01-0.19$ & $55 \%$ & $58 \%$ & $55 \%$ & $65 \%$ & $32 \%$ \\
Feb,15th, 2008 & $0.19-0.29$ & $38 \%$ & $40 \%$ & $38 \%$ & $29 \%$ & $60 \%$ \\
\cline { 2 - 6 } & $\geq 0.3$ & $3 \%$ & 0 & $4 \%$ & 0 & $8 \%$ \\
Difference of & $\leq 0$ & $12 \%$ & $4 \%$ & $6 \%$ & $23 \%$ & $23 \%$ \\
Feb,4th ,2007 and & $0.01-0.19$ & $61 \%$ & $64 \%$ & $66 \%$ & $72 \%$ & $68 \%$ \\
Feb,15th, 2008 & $0.19-0.29$ & $25 \%$ & $32 \%$ & $27 \%$ & $5 \%$ & $9 \%$ \\
& $\geq 0.3$ & $3 \%$ & 0 & $2 \%$ & 0 & 0 \\
\hline
\end{tabular}

The results of sample field investigation showed that the NDVI difference decrease more than 0.30 , sugar contain reduced $0.8 \%$ to $1.0 \%$, if the NDVI difference decrease $0.2 \sim 0.3$, the sugar contain reduced $0.5 \%$, if the NDVI difference decrease $0.1 \sim 0.2$, the sugar contain reduced $0.2 \%$. Consequently, we can accord the area of percent of sugar-cane NDVI different to calculate the losing of sugar. In view of the sugar-cane planting area in 2007/2008 years crushing season in Guangxi province, the losing of sugar approach $2.56 \times 108 \mathrm{~kg}$.

\section{CONCLUSION}

Based on the above study and analysis, some conclusions can be drawn as follows:

(1) It is an effective way to reflect the spatial distribute information of cold chilling and freeze injury with using the changes of sugar-cane NDVI of former and after disaster based on the sugar-cane planting spatial distribution information which were carried out by using multi-phase EOS/MODIS data.

(2) The field sample investigation data of using GPS was integrated with the changes of sugar-cane NDVI of former and after disaster, the evaluation of region sugar-cane suffer from cold chilling and freeze injury losing could quickly and exactly realize.

(3) Monitoring cold chilling and freeze injury and evaluating losing of sugar-cane using Remote Sensing and Global Positioning System are great economic significance. 


\section{ACKNOWLEDGEMENTS}

This research was supported by National Key Technologies R\&D Program (2007BAD30B and 2008BAD08B01), It is also supported by the China Meteorological Administration new technology extend project (CMATG2006M42), Sincerely thanks are also due to Guangxi Climate center and National Satellite Meteorology Center for providing the data for this study.

\section{REFERENCES}

Cheng Qian, Huang J F. Analyses of the Correlation BetweenRice LAI and Simulated MODIS Vegetation Indices. RedEdge PositionU). Transactions of the CSAE, 2003, 19(5):104-108.

Gupta R k, Prasad S, Seshasai M V R, et a1. The estimation of surface temperature over an agricultural area in the state of Haryana, Panjab, India and its relation with the normalized diference vegetation index(NDVI), using NOAA-AVHRR data[J]. InternationalJournal of Remote Sensing, 1997, 18: 3729-3741.

Huete A, Justice C, Leeuwen V. MODIS Vegetation Index(MOD1 3)Version 3(Z). April 1999 Algorithm Theoretical Basis Document.

Kontoes C,Wilkinson G G,Burril A,etal. An Experimental System for the Integration of GIS Data in Knowledge Based Image Analysis for Remote Sensing of Agriculture [J]. International Journal of Geographical Information Systems, 1993,7(3):247-262

Murthy C S,Raju P V,Badrinath K V S Classification of Wheat Crop with Multi-temporal Images: Performance of Maximum Likelihood and Artificial Neural Networks[J].Int J Remote Sensing,2003,24(23):4871-4890

Van D G, Owe M. On the relationship between therm al emissivity and the normalized difference vegetation index for natural surfaces[J]. International Journal of Remote Sensing, 1993, 14: 1119-1121.

Yang Bangjie, Wang Maoxin, Pei Zhiyuan. Monitoring Freeze Injury to Winter Wheat Using Remote Sensing Transactions of the CSAE. 2002, 18(2):136-140

Zhang Xuefen, Chen Huailiang, Zheng Youfei. Monitoring the Freezing Injury of Winter Wheat by Remote Sensing. Journal of Nanjing Institute of Meteorolog, 2006, 29(1):94-100

Zhao M S,Fu C B,Yan X D etal. Study on the relationship between different ecosystem and climate in China using NOAA/AVHRR data. Acta Geographica Sinica, 2001, 56(3):287296.(in Chinese)

Zheng Y R,Zhou G S A forest vegetation NPP model based on NDVI. Acta Phytoecologica Sinica, 2002, 24:9-12.(in Chinese) 